motorways on weak steel posts can steer cars back on the right carriageway even at impact speeds of 70 m.p.h. or over. Again, damage to the vehicle is reduced, and the danger of head-on impacts with approaching cars is minimized.

Much of the work, of course, is not directly concerned with safety. The traffic section includes predictions of the number of rehicles on British roads up to the year 2010 (27 million by 1980, 40 million in 2010 ), and gives details of the traffic flows in towns and on the M4 motorway. It also describes the problem a driver faces when approaching a green light at high speed; if it changes to amber too late for him to stop, should he brake and risk skidding or accelerate and hope to be clear of the cross traffic ? The dilemma is common enough, but does not seem to have been seriously studied before; the report suggests a solution based on a speed detector which will in some circumstances give fast drivers an extension of the green signal.

In addition, the report describes the problems of road building, both in temperate and tropical climates. One of the responsibilities of the laboratory is to provide technical aid for developing countries, where the development of roads is often an essential forerunner of economic development. Last week, the laboratory opened new buildings at Crowthorne in Berkshire and, for the first time since the war, the work of the laboratory is carried out on one site. The new buildings cost $£ 3.5$ million, which is also what the laboratory costs to run each year. The figure given in the Civil Estimates for support for traffic research in 1966 is $£ 3.52$ million, showing a sharp increase over the 1965 figure of $£ 2 \cdot 66$ million.

\section{Detecting Turbulence}

WHILE the causes of clear air turbulence remain obscure, it is clear that it is often associated with temperature gradients in the atmosphere. Recent, work at Oxford and Reading Universities may offer a way of detecting the gradients, and, by inference, the turbulence. If this can be detected far enough ahcad of aircraft, evasive action can be taken.

This, clearly, is the argument which has encouraged the Science Research Council to award a grant of $\mathfrak{L 8 9 , 0 0 0}$ to Dr J. T. Houghton of the Clarendon Laboratory at Oxford and to Dr S. D. Smith of the Department of Physics at Reading. Together they have developed a radiometer which detects the infra-red radiation from carbon dioxide in the atmosphere, and the instrument is now being produced in its engineered form by Elliott Bros. (London), Ltd., of Frimley, near Aldershot. In its present form the radiometer will be used in an American satellite, called Nimbus D, to be launched by NASA in late 1969, and is intended to provide a world-wide survey of the temperature of the atmosphere up to about 30 miles. At different heights in the atmosphere, the carbon dioxide band occurs at different wavelengths, so that by choosing a certain wavelength a certain height can be studied by the instrument in the orbiting satellite. In the Nimbus experiment, the temperature of the atmosphere will be studied from cloud top height to about 30 miles, to an accuracy of about $\pm 1^{\circ} \mathrm{C}$.

It is also hoped to develop the instrument for the detection of clear air turbulence. In this role, it would be mounted in the front of the aircraft, scanning the region of the atmosphere ahead. By detecting temperature gradients, it might be possible to avoid regions of clear air turbulence. Dr Houghton believes that the range of the instrument could be 50 miles, not as great as the operators of supersonic transports might wish-they hope for a range of 100 miles-but better than nothing. The SRC certainly believes the instrument has a commercial future, and has asked the NRDC to consider further development of the design with an industrial firm.

\section{Rheumatism, Tractable and Otherwise}

TuE MRC Rheumatism Research Unit housed in the Canadian Red Cross Memorial Hospital at Taplow celebrated its twentieth anniversary last week. Although it had no dramatic announcements to make, it is proud of a steady advance in the treatment of the more tractable forms of rheumatism. The term itself includes any disease of the joints which causes pain and which is aggravated by movement. Professor Bywaters, honorary director of the unit, says that there were 83 different rheumatic conditions at the last count, ranging from sprains to degenerative conditions due to ageing, metabolic disorders such as gout, infective conditions such as rheumatic fever and arthritic diseases the cause of which is unknown.

The unit is chiefly concerned with the arthritic group of disorders, and the most promising line of research centres around the possibility that rheumatoid arthritis involves an immune reaction of the body to its own tissues. Certainly auto-immune reactions like these have been demonstrated in mice and can cause a syndrome similar in appearance to rheumatoid arthritis. But this is only one possibility. Some workers even claim to have found characteristic organisms in the synovia of patients with this disease, suggesting an infective mechanism, but this is in dispute. But there are certainly infective mechanisms in rheumatic fever, one of the more unpleasant possibilities following a sore throat. Over the years the treatment of rheumatoid arthritis has improved considerably, especially with children. Until recently, children with the chronic disease were confined to bed, which often made their condition worse. Nowadays treatment is designed to minimize deformity so that children can lead full lives when they recover-as in time they do. Splinting and physiotherapy play a part, as does the use of drugs to reduce pain and inflammation. Salicylates and corticosteroids are frequently used, but neither is free from side effects; corticosteroids in massive doses, for example, can control pain and inflammation but may cause a child to fail to grow in height. The problem is to weigh the advantages of treatment against the disadvantages of side effects.

\section{Fossil Fishes}

\section{Dr Alan J. Charig writes:}

THE Linnean Society of London is marking the retirement of Dr Errol I. White as Keeper of Palaeontology in the British Museum (Natural History) and President of the Society with a special volume of articles mainly on fossil fishes, and five of the twenty papers therein were read at a one-day symposium on June 23. One striking feature of the paper by Professor E. Jarvik of 